36. Reed, P. W., and Lardy, H. A.: A23187: A divalent cation ionophore. J. Biol. Chem., 247: 6970 (1972).

37. Satir, P.: Ionophore-mediated calcium entry induces mussel gill ciliary arrest. Science, 190: 586 (1975).

38. Selinger, Z., Eimerl, S., and Schramm, M.: A calcium ionophore simulating the action of epinephrine on the $\alpha$ adrenergic receptor. Proc. Natl. Acad. Sci. U.S. A., 71: 128 (1974)

39. Shelanski, M. L., Gaskin, F., and Cantor, C. R.: Microtubule assembly in the absence of added nucleotides. Proc. Natl. Acad. Sci. U. S. A., 70: 765 (1973).

40. Somlyo, A. P., Garfield, R. E., Chacko, S., and Somlyo, A. V.: Golgi organelles response to the antibiotic X537A. J. Cell Biol., 66: 425, (1975).

41. Spock, A., Heick, H. M. C., Cress, A., and Logan, W. S.: Abnormal serum factor in patients with cystic fibrosis of the pancreas. Pediat. Res. 1: 173 (1967)

42. Trump, B. F., and Arstila, A. U.: Cell membranes and disease processes. In B. F. Trump and A. U. Arstila: Pathobiology of Cell Membranes, p. 1 (Academic Press, New York, 1975)

43. Trump, B. F., Crocker, B. D., and Mergoner, W. J.: The role of energy metabolism, ion and water shifts in the pathogenesis of cell injury. In: $G$ W. Ricter and D. G. Scarpelli: Cell Membranes: Biological and Pathological

Copyright (ㅇ 1978 International Pediatric Research Foundation, Inc $0031-3998 / 78 / 0012-0001 \$ 02.00 / 0$
Aspects, p. 84 (The Williams \& Wilkins Co., Baltimore, 1971).

44. Trump, B. F. McDowell, E. M., Barret, L. A., Frank, A. L., and Harris, C. C.: Studies of ultrastructure, cytochemistry and organ culture of human bronchial epithelium. In: F. Karbe and J. E. Parks: Experimental Lung Cancer Carcinogenesis and Bioassay, p. 548, (Springer-Verlag, New York, 1974).

45. Weisenberg, R. C.: Microtubule formation in vitro in solutions containing low calcium concentrations. Science, 177: 1104 (1972).

46. Wong, D. T., Wilkinson, J. R., Hanill, R. L., and Horng, J. S.: Effect of antibiotic ionophore A23187 on oxidative phosphorylation and calcium transport of liver mitochondria. Arch. Biochem. Biophys. 156: 578 (1973)

47. Dr. James Conover is the recipient of Cystic Fibrosis Foundation Research Scholar Award.

48. This work was supported in part by grants from the National FoundationMarch of Dimes (1-392) and by the Cystic Fibrosis Foundation.

49. Requests for reprints should be addressed to: Bruce I. Bogart, Ph.D., New

York University Medical Center, Department of Cell Biology, 550 First Avenue, New York, New York 10016 (USA)

50. Received for publication October 11, 1976

51. Accepted for publication April 26, 1977.

Printed in U.S.A.

Pediat. Res. 12: 24-26 (1978)

Absorption

intestinal osmolality

intraluminal water content polyethylene gylcol

polymerized glucose

\title{
Intestinal Osmolality and Carbohydrate Absorption in Rats Treated with Polymerized Glucose
}

\author{
FREDRIC DAUM, ${ }^{(8)}$ MICHAEL I. COHEN, HELEN MCNAMARA, AND LAURENCE FINBERG \\ Department of Pediatrics, Montefiore Hospital and Medical Center, Albert Einstein College of Medicine, Bronx, \\ New York, USA
}

\section{Summary}

The intestinal osmolal physiology and absorption of comparable preparations of polymerized glucose and glucose were evaluated in isolated segments of rat duodenum. The acute rise in the osmolality of the succus entericus after $5 \%$ polymer injections $(298 \mathrm{mOsm} / \mathrm{kg}$ at $3 \mathrm{~min}, 311 \mathrm{mOsm} / \mathrm{kg}$ at $30 \mathrm{~min}$ ) was significantly less than that noted after $5 \%$ glucose (387 $\mathrm{mOsm} / \mathrm{kg}$ at $3 \mathrm{~min}, 351 \mathrm{mOsm} / \mathrm{kg}$ at $30 \mathrm{~min}$ ). At $60 \mathrm{~min}$ a steady state had been established and no significant difference was found. Ten percent polymer was superior to $10 \%$ glucose as it also produced a lower luminal osmolality $(351 \mathrm{mOsm} / \mathrm{kg}$ versus $427 \mathrm{mOsm} / \mathrm{kg}$ at $30 \mathrm{~min}$ ). Luminal polyethylene glycol concentrations revealed comparable increases in intraluminal water content after $10 \%$ polymer and $5 \%$ glucose $(22 \%$ versus $25 \%$ al: $30 \mathrm{~min}$ ). After polymer injections, 4 times as much glucose was present in the mucosa as in the succus, whereas, after $5 \%$ glucose injections, a high concentration of glucose remained in the succus.

These results indicate that polymer solutions produce lower luminal osmolality than glucose solutions of similar weight. Additionally, enhanced glucose absorption by the mucosal cell is suggested in animals injected with polymer. Polymerized glucose should, therefore, provide twice the calories of glucose without a disparate increase in the intestinal osmolality and intraluminal diffusion of extracellular water.

\section{Speculation}

A polymerized glucose preparation, when administered orally, produces a lower immediate intraluminal solute content and osmolality than a glucose solution of the same concentration by weight when each has comparable electrolytes. Hydrolysis of the polymer within the intestinal lumen and on contact with the brush border of the intestine provides nutrient without increase in water movement into the proximal small bowel. Because of these properties, such a polymer may be useful in the oral nutritional rehabilitation of neonates and infants with diarrhea. It remains to be seen whether the pathogenesis of the diarrheal state may also prove to be of significance in determining the beneficial effect of this therapy.

Polymerized glucose represents a carbohydrate source with low electrolyte and mineral content prepared by acid-enzyme hydrolysis of selected cornstarch. The process yields a hydrolysate with $80 \%$ amylose, $20 \%$ amylopectin, and small amounts of glucose, maltose, and isomaltose. The polymer is predominantly medium chain length glucose moieties although a variety of lengths are present. Free glucose represents less than $2 \%$ of all the carbohydrate present whereas a chain length of 5-9 glucose units comprises almost $50 \%$ of the polymer. The polymers are mainly linear in their spatial configuration. The glucose 
Table 1. Osmolalities (milliosmoles per $\mathrm{kg}$ ) \pm 1 SEM of initial solutions and rat succus entericus in separate experiments at 3, 30, and $60 \mathrm{~min}$ afier intraduodenal infusions into isolated gut loops

\begin{tabular}{|c|c|c|c|c|c|c|}
\hline & Initial solution & Succus (3 min) & Initial solution & Succus $(30 \mathrm{~min})$ & Initial solution & Succus $(60 \mathrm{~min})$ \\
\hline $5 \%$ Polymer & $186 \pm 6$ & $298 \pm 3$ & $173 \pm 2$ & $311 \pm 3$ & $168 \pm 3$ & $320 \pm 4$ \\
\hline $5 \%$ Glucose & $392 \pm 7$ & $387 \pm 8$ & $405 \pm 4$ & $351 \pm 5$ & $391 \pm 4$ & $345 \pm 13$ \\
\hline Saline & $286 \pm 9$ & $335 \pm 24$ & & & & \\
\hline
\end{tabular}

residues are attached by $\alpha-1,4$-glycosidic bonds with only a small amount of branching at the $\alpha$-1,6-glycosidic bonding site (6).

Because of the 5-fold increase in molecular weight of polymer (mol wt 1,000) compared to that of glucose, the osmolality of a solution of polymerized glucose is one-fifth that of a free glucose solution of the same concentration by weight. The low osmolality and rapid hydrolysis of polymer and the subsequent intestinal absorption of the glucose suggest that it may provide carbohydrate as a source of calories without precipitating a marked intraluminal diffusion of water.

The present studies were designed to compare the osmolal physiology and carbohydrate absorption in rat intestinal loops after placement of either polymerized glucose or simple glucose solutions of identical weight/volume concentrations.

\section{MATERIALS AND METHODS}

Adult, male Sprague-Dawley rats, weighing 200-300 g, received regular breeder chow and water ad libitum for 7 days. They were given only water for $12 \mathrm{hr}$ before experimentation. Each animal was lightly anesthetized with open drop ether and the abdominal musculature incised along its cephalocaudad axis. Ligatures were secured around the pylorus and $6 \mathrm{~cm}$ distally without interfering with the vascular arcade from the mesentery to the bowel. This technique established an isolated duodenal loop in continuity with its venous and arterial blood supply.

Before each study, appropriate amounts of polymer and glucose powder were dissolved in sterile water to a volume of 1 liter and made up to either a 5 or $10 \%$ concentration. Identical amounts of electrolyte were added to each solution to give the following concentrations: $\mathrm{Na}^{+} 49 \mathrm{mEq} / \mathrm{liter}, \mathrm{K}^{+} 20 \mathrm{mEq} / \mathrm{liter}$, $\mathrm{Cl}^{-} 30 \mathrm{mEq} / \mathrm{liter}$, citrate ion $29 \mathrm{mEq} /$ liter, phosphate ion 10 $\mathrm{mEq} /$ liter. Analyses for glucose concentration were performed on each solution after preparation to check for spontaneous hydrolysis.

One milliliter of either polymer or glucose was then injected into the proximal portion of the isolated loop using a 23-gauge needle. The succus entericus was completely withdrawn at either 3,30 , or $60 \mathrm{~min}$ after the initial injection and frozen for subsequent analysis of osmolality and glucose concentration. The intestinal segment was then immediately excised adjacent to both ligatures, opened on its antimesenteric border, wiped gently with gauze, and the mucosa scraped and stored for later analysis of glucose concentrations. Eight rats received polymer and six received glucose in each study. In addition, in the 3-min protocol, four rats were injected with isotonic saline while four were killed in sham experiments to demonstrate any physiologic changes that might occur as a result of the operative technique. The osmolality of the injected solutions for each set of experiments and the succus entericus was measured by the Fiske automatic osmometer. Glucose concentrations of the initial solutions, the succus and the duodenal mucosal scrapings were determined by the Glucostat method (7).

In order to estimate intraluminal shifts in water caused by polymer and glucose, polyethylene glycol was employed as a nonabsorbable, water-soluble inert marker. The concentration of polyethylene glycol in the succus was determined $30 \mathrm{~min}$ after injection according to the method of Boulter and McMichael (3). This is a modification of the turbidimetric method of Hyden (5). Intestinal mucosal water was measured by drying
Table 2. Comparison of osmolal (milliosomoles per $\mathrm{kg}$ ) concentrations \pm 1 SEM of $5 \%$ and $10 \%$ preparations of polymer and free glucose as parent solution and 30 min after injection into isolated rat small intestinal segments

\begin{tabular}{lcc}
\hline & Initial solution & Succus (30 min) \\
\hline $5 \%$ Polymer & $173 \pm 2$ & $311 \pm 3$ \\
$5 \%$ Glucose & $405 \pm 4$ & $351 \pm 5$ \\
$10 \%$ Polymer & $237 \pm 9$ & $351 \pm 2$ \\
$10 \%$ Glucose & $682 \pm 7$ & $427 \pm 20$ \\
\hline
\end{tabular}

Table 3. Rat mucosal tissue water concentrations expressed as a percentage of mucosal wet weight 3 min after injection of various preparations

\begin{tabular}{lc}
\hline & $\%$ Wet wt mucosa $\mathrm{t} 3 \mathrm{~min}$ \\
\hline $5 \%$ Polymer & 81 \\
$5 \%$ Glucose & 81 \\
Saline & 82 \\
Sham & 80 \\
\hline
\end{tabular}

Table 4. Intraluminal polyethylene glycol concentrations expressed as percentage of increase in luminal water content at $30 \min ^{1}$

$\%$ Increase in

luminal water content at $30 \mathrm{~min}$

\begin{tabular}{lrlr}
\hline $5 \%$ Polymer & 18 & $10 \%$ Polymer & 22 \\
$5 \%$ Glucose & 25 & $10 \%$ Glucose & 43 \\
Saline & 1 & Saline & 1 \\
\hline
\end{tabular}

1 These values demonstrate the flux of water with these various solutions and at different osmolal concentrations.

the excised mucosa to a constant weight at room temperature over a dessicant in a vacuum chamber.

The obvious disparity in the initial glucose concentrations of the various parent solutions of polymer remains unexplained. Twenty-six separate experiments were performed and the glucose concentration in the polymer ranged from $0.2-2.7 \mathrm{~g} / \mathrm{dl}$. All solutions were prepared freshly for each experiment. Glucose concentrations were measured by the Glucostat method without possible previous contamination of glassware by amylase. Hydrolysis of polymer probably takes place but we and the manufacturer are unable to account for this wide variation in glucose concentration.

\section{RESULTS}

\section{OSMOLALITY}

Table 1 shows the osmolality of the initial solutions, and the succus entericus at 3,30 , and $60 \mathrm{~min}$ after the injection of $5 \%$ polymer, $5 \%$ glucose, and isotonic saline. Succus entericus could not be obtained from the sham-operated rats.

In the 3- and 30-min experimetns, the rise in the osmolality of the succus after injection of the polymer solution is significantly less than that noted after $5 \%$ glucose with a $P$ value of $<0.002$ by $t$-test analysis. By $60 \mathrm{~min}$ a steady state has been 
Table 5. Glucose concentrations (grams per dl) of parent solutions, succus entericus and mucosa, at 3, 30, and 60 min in rats with prepared isolated duodenal loops in continuity with their mesenteric blood supply ${ }^{1}$

\begin{tabular}{|c|c|c|c|c|c|c|c|c|c|}
\hline & \multirow{2}{*}{$\begin{array}{c}\text { Initial solu- } \\
\text { tion }\end{array}$} & \multicolumn{2}{|c|}{$3 \mathrm{~min}$} & \multirow{2}{*}{$\begin{array}{c}\text { Initial solu- } \\
\text { tion }\end{array}$} & \multicolumn{2}{|c|}{$30 \mathrm{~min}$} & \multirow{2}{*}{$\begin{array}{l}\text { Initial solu- } \\
\text { tion }\end{array}$} & \multicolumn{2}{|c|}{$60 \mathrm{~min}$} \\
\hline & & Succus & Mucosa & & Succus & Mucosa & & Succus & Mucosa \\
\hline $5 \%$ Polymer & 0.2 & 0.2 & 0.9 & 1.3 & 0.6 & 0.7 & 1.3 & 0.9 & 0.6 \\
\hline $5 \%$ Glucose & 4.9 & 3.8 & 0.7 & 4.9 & 2.9 & 0.9 & 4.4 & 2.0 & 0.5 \\
\hline Saline & 0.0 & 0.0 & 0.1 & & & & & & \\
\hline Sham & & & 0.1 & & & & & & \\
\hline
\end{tabular}

${ }^{1}$ Each time period is a separate experiment. See text for explanation of variation in initial glucose concentrations.

established and little difference exists between the osmolalities found in the succus with either of the two solutions.

Experiments using $10 \%$ polymer and $10 \%$ free glucose (Table 2) show that a $10 \%$ polymer solution produces a lower luminal (succus) osmolality at $30 \mathrm{~min}$. The $10 \%$ polymer preparation produced a change in intestinal osmolality no greater than that noted after a $5 \%$ free glucose solution.

\section{TISSUE WATER}

No differences in mucosal tissue water, expressed as a percentage of the wet weight of the scraped mucosa, were observed 3 min after injection under any of the experimental conditions (Table 3). However, determinations of the polyethylene glycol concentrations, expressed as a percentile change in the luminal water content of the succus at $30 \mathrm{~min}$ (Table 4), revealed an $18 \%$ water increase after $5 \%$ polymer compared to a $25 \%$ increase after $5 \%$ glucose. With $10 \%$ polymer, there was a $22 \%$ increase in intraluminal water, whereas a $43 \%$ rise occurred with $10 \%$ glucose and the osmolality was not yet at steady state. A $10 \%$ polymer solution resulted in no greater influx of intestinal water than did a $5 \%$ free glucose solution.

\section{GLUCOSE}

The glucose concentrations of the parent solutions, succus entericus and duodenal mucosa, at 3,30, and $60 \mathrm{~min}$ are noted in Table 5. Little glucose appears in the succus $3 \mathrm{~min}$ after polymer injection, whereas approximately 4 times as much glucose is present simultaneously in the mucosa $(P<0.001)$. With infusion of $5 \%$ free glucose, a high concentration of glucose remains in the succus whereas much lesser concentrations are present in the mucosa. Thirty and $60 \mathrm{~min}$, respectively, after glucose injection there is still 3 and 4 times as much glucose in the succus as in the mucosa $(P<0.001)$. Control animals represented by saline injections or sham operations at 3 min demonstrate no effect on mucosal glucose.

\section{DISCUSSION}

These results indicate that both $5 \%$ and $10 \%$ polymer solutions permit a succus entericus of low osmolality as opposed to glucose solutions of similar weight. This low osmolality which reflects the significantly lower glucose concentration noted in the succus entericus after polymer injection is directly responsible for the small increases in luminal water content observed after injection of equal concentrations by weight of glucose and polymer.

The clinical advantages of such a polymer preparation are readily apparent when one considers that a greater caloric content can thus be offered to an infant with diarrhea without increasing luminal water volume with consequent fecal water and electrolyte loss. After polymer there is a 4-fold simultaneous increase in mucosal glucose, whereas $3 \mathrm{~min}$ after glucose injec- tion, a much higher concentration of glucose remains in the succus. Experiments in humans indicate that blood glucose levels after polymer ingestion rise commensurately with those after comparable feedings of an oral glucose solution (4). In these in vivo experiments, simultaneous glucose concentrations were not measured from the portal vein and information is not available on blood glucose homeostasis which may vary for many reasons.

The mechanisms by which polymer is digested and metabolized remain to be elucidated. It is possible that pancreatic amylase initially hydrolyzes polymer to maltose, maltotriose, and a mixture of dextrins containing $\alpha 1,6$ branches. Since pancreatic amylase hydrolyzes only $\alpha 1,4$ linkages and the $\alpha 1,6$ branching links, glucose is not one of the products. Glucose is only released when oligosaccharides come into contact with the brush border of the intestine. The role of pancreatic amylase in the metabolism of polymer remains unclear, but studies by Allan et al. (1) and Berry et al. (2) in children with cystic fibrosis and essentially no amylase indicate that polymer produced a normal rise in blood glucose after ingestion and served as an effective caloric source for long term nutritional management, as shown by weight and linear growth.

\section{CONCLUSION}

A rat model was designed to evaluate intestinal osmolality and carbohydrate absorption of polymerized glucose. Studies indicate that polymerized glucose produces a lower immediate intraluminal solute content and osmolality than a glucose solution of the same concentration by weight. Small increases in intraluminal water content were also noted after polymer. These physiologic properties of polymerized glucose suggest that it may be offered as a nutritional source to patients with diarrhea without increasing fecal fluid and electrolyte loss.

\section{REFERENCES AND NOTES}

1. Allan, J. D., Mason, A., and Moss, A. D.: Nutritional supplementation in treatment of cystic fibrosis of the pancreas. Amer. J. Dis. Child., 126: 22 (1973).

2. Berry, H. K., Kellog, F. W., Hunt, M. M., Ingerb, R. L., Richter, L., and Gutjahr, C.: Dietary supplement and nutrition in children with cystic fibrosis. Amer. J. Dis. Child., 129: 165 (1975).

3. Boulter, J. M., and McMichael, H. B.: Modification of polyethylene glycol estimation suitable for use with small mammals. Gut, 11: 268 (1970).

4. Drash, A.: Unpublished data as cited in Polycose Monograph. Ross Laboratories, Columbus, Ohio, (1974).

5. Hyden, S.: A turbidimetric method for determination of higher polyethylene glycol in biological materials. K. LantbrHögsk. Annir., 18: 139, (1956)

6. Polycose Monograph, Ross Laboratories, Columbus, Ohio, (1974).

7. Saifer, A., and Gerstenfeld, S.: The photometric microdetermination of blood glucose with glucose oxidase. J. Lab. Clin. Med., 51: 448 (1958).

8. . Requests for reprints should be addressed to: Fredric Daum, MD., Department of Pediatrics, North Shore University Hospital, 300 Community Drive, Manhasset, New York 11030 (USA).

9. Received for publication December 8, 1977.

10. Accepted for publication May 6, 1977. 